\title{
Dermoid Cyst and its bizarre presentation
}

\author{
Pramila Pradhan, ${ }^{1}$ Meeta Thapa' \\ 'Department of Obstetrics and Gynaecology, Nepal Medical College Teaching Hospital, Jorpati, Kathmandu, Nepal.
}

\section{ABSTRACT}

Dermoid cysts or mature cystic teratoma are the most common type of ovarian germ cell tumor usually occurring in the reproductive age group. They are commonly unilateral and $10-12 \%$ can be bilateral. They are commonly multicystic and contain sebaceous fluid as well as tissue of three germ cell layers e.g. ectoderm (skin, hair, brain) mesoderm (muscle, fat ,teeth ,bone, and cartilage) and endoderm (mucious and ciliated epithelium). These teratomas usually arise from the gonads but has been found anywhere in the body. Their site, size and clinical presentations are extremely variable causing confusion with medical and surgical diseases, acute emergency due to rupture and torsion , bowel and bladder injuries, and pregnancy etc. The malignant teratoma occurs at 3-4\% only among ovarian carcinoma. The malignant transformation in benign cysts is a rare occurrence with $1-2 \%$ cases and squamous cell carcinoma being the commonest. This review is undertaken to study the different presentations produced by these tumors.

Keywords: bizarre; cyst; dermoid.

\section{INTRODUCTION}

Mature cystic teratomas commonly called dermoid cysts, are the most common benign germ cell tumors of ovary, comprising up to $30 \%$ of all ovarian tumours. ${ }^{1}$ They are encountered predominantly in women in their second and third decades of life but can occur in any age group 1-96 years. ${ }^{2}$ Histologically, they display a varying admixture of elements of one or more of the three germ cell layers: ectoderm (skin, brain) mesoderm (muscle, fat, teeth, bone and cartilage) and endodermal (mucinous or ciliated epithelium gastrointestinal, bronchial, thyroid tissue). ${ }^{3}$ Pathologically, teratomas are classified into three groups: Mature (cystic/solid, benign), Immature (malignant) and Monodermal (highly specialized e.g. Struma ovarii, carcinoid tumors, neural tumors). Teratomas most commonly arise in the gonads but have also found in the anterior mediastinum, retro-peritoneum and gastrointestinal tract. ${ }^{4}$ Despite the benign nature of these neoplasms, considerable interest have been paid on them because of unusual histogenesis caused by the totipotency of these tumors that may give to any body structure or tissues and even the structure similar to fetus. ${ }^{5}$ Despite a number of conflict theories to explain the histogenesis of teratomas, the most probable ones are misplaced blastomere and pathenogenetic development of a germ cell. Whatever the reason for the development of teratomas may be, these tumors seemingly arise from the totipotential embryonic cells broken away from the normal developmental pathway to form the various fetal tissues.$^{6}$ The majority of teratomas may be symptoms free but giant ovarian teratomas commonly present with acute abdominal pain caused by adnexal torsion, rupture or infection or abdominal distention due to the rapid growth of a large, unilateral tumor undergoing capsular distention, hemorrhage or necrosis. ${ }^{7}$ The mature teratomas sometimes may be adherent to small and large bowel causing intestinal obstruction or fistula

Correspondence: Dr. Pramila Pradhan, Department of Obstetrics and Gynaecology, Nepal Medical College Teaching Hospital, Jorpati, Kathmandu. Nepal. Email: drpramilapradhan@gmail.com, Phone: $+977-9841490496$. 
formation. ${ }^{8}$ Malignant transformation of the mature elements within the dermoid cyst is a rare complication, occurring in only $1-2 \%$ of cases with squamous cell carcinoma being the most common type (80-90\%) followed by adenocarcinoma , Carcinoid, Sarcoma, Oesteosarcoma. ${ }^{9}$ At ultrasound mature teratomas are characterised by echogenic sebacious material and calcification. At Computated Tomography (CT) fat attenuation within a cyst is diagnostic. CT and Magnetic Resonance Imaging (MRI) are straightforward as these modalities are more sensitive for fat within the cyst which is diagnostic for mature teratoma ${ }^{7}$ Their clinical features vary from completely asymptomatic to bizarre features confusing with medical, surgical diseases, acute emergency due to rupture or torsion of the cyst, bowel or bladder injuries and malignant transformation.

This article tries to present different presentations, some of which are bizarre nature encountered with mature teratomas.

\section{Size}

The size of a dermoid cyst may be extremely variable. They can be found accidentally when they measure just around $1 \mathrm{~cm}$ and are situated inside the ovary without causing ovarian distortion. (Figure. 1).

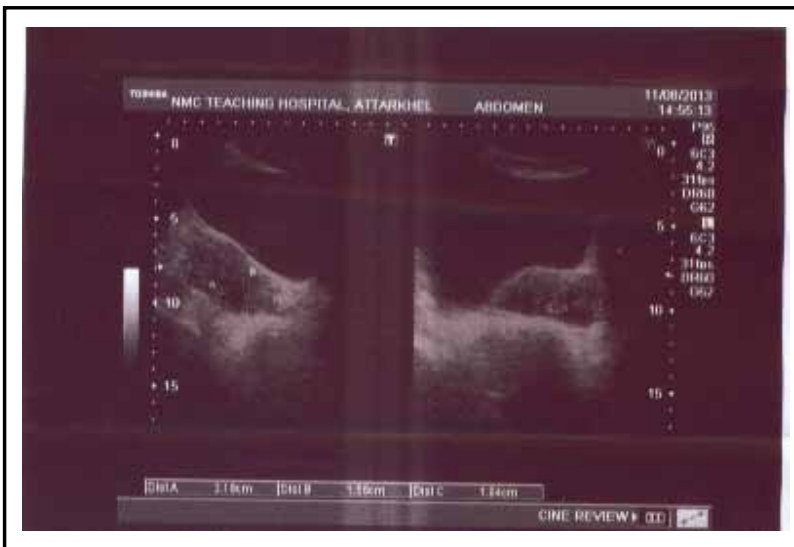

Figure 1. Hyperechoic small ovarian Dermoid cyst.

They have a growth rate of $1.8 \mathrm{~mm} /$ year in premenopausal women and rarely grow larger than a melon size, but they can also have gigantic dimensions of 30-40cms. (Figure 2). ${ }^{10-12}$ The tumor tend to enlarge until specific organs are functionally influenced or incidentally discovered by ultrasonography. Massive ovarian tumors can mimic actites and usually present with obvious abdominal distention but in the presence of severe obesity they may be overlooked. ${ }^{13}$ There have been reports in both the medical and lay press of surgical extirpation of simple fluid filled cysts weighing as much as $300 \mathrm{lbs}$ and draining 80 litres of fluid. ${ }^{13}$ An ovarian teratoma of 303.2 pounds $(134.7 \mathrm{~kg})$ removed enbloc has been described in a bed ridden lady for the previous 2 years and house bound for 6 years due to enlarging ovarian dermoid cyst. Despite the large size, there is a one third chance of finding a malignant suggesting that all of these large masses should be removed intact whenever possible. ${ }^{14}$
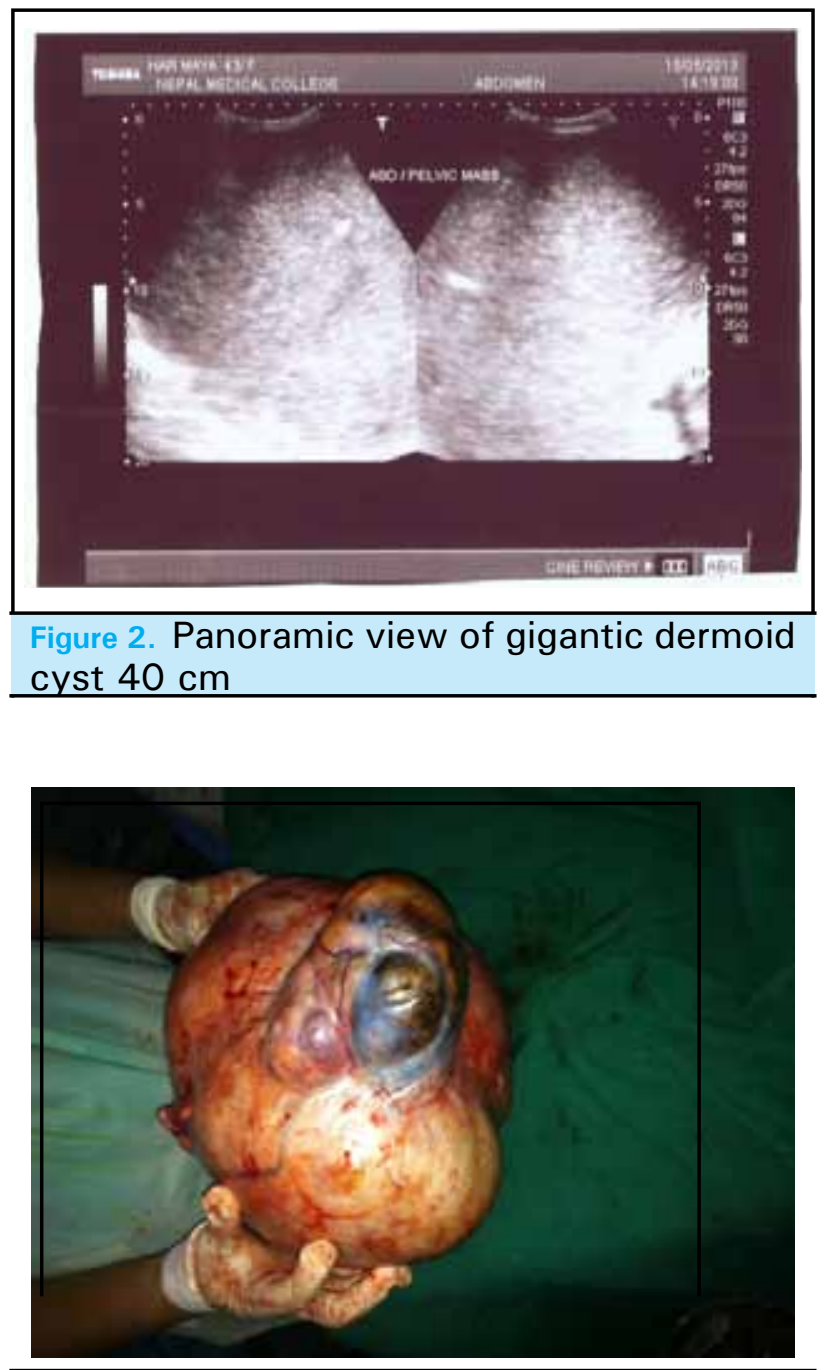

Figure 3. Huge Dermoid cyst.

\section{Site}

Dermoid cysts occur most commonly in the ovary but the cases of extragonadal origin have been described e.g. anterior mediastinum, retroperitoneal, sacrococcygeal area, head, neck and central nervous system (CNS). Dermoid cysts have been reported throughout the gastrointestinal (GI) tract and associated organs include caecum, ${ }^{15}$ rectum, ${ }^{16}$ pancreas. ${ }^{17}$ In the GI tract mesenteric dermoid cysts are the most common site for ovarian teratoma. ${ }^{18-22}$ Omentum is also the most common extragonadal site of dermoid 
cyst. The omentum, because of its special role in intra-abdominal inflammatory defence process, is probably the main location for secondary implantation for the tumor. ${ }^{21,22}$

\section{Parasitic dermoid cyst}

Parasitic dermoid cyst is extremely rare entities and their actual incidence is reported to be $0.4 \%$ of all ovarian teratoma. ${ }^{23}$ Several theories exist to explain their occurrence. The first theory proposes the development within a supernumerary or ectopic ovary which may occur due to implantation of ovarian tissue after surgical procedure or inflammation such as pelvic inflammatory disease. Supernumerary ovaries may also occur as a result of abnormal arrest of germinal cells into the dorsal mesentery during their embryonic migration. ${ }^{24}$ Another theoretical mechanism is auto amputation and re -implantation of the dermoid cyst as a result of torsion. If the torsion of the tumor is subacute, an inflammatory response may occur which causes the tumor to become adherent to the surrounding structures and neovascularization may occur. The tumor may become parasitic by detaching itself from its original blood supply. ${ }^{23}$ Pouch of Douglas seems to be the best location for the parasitic dermoid. ${ }^{22}$ Recently a new site for parasitic dermoid cyst on the reflection of utero-vesical pouch onto anterior abdominal wall which is known anatomically as the median umbilical fold have been reported. ${ }^{25,26}$ Some of these parasitic dermoid cysts have been found to incidentally contain mobile spherules. The reason for the formation of such large spherules is still unknown, although it is proposed that hypovascularity could be a possibility. ${ }^{27,28}$ The clinical presentation of the reported parasitic teratomas of the pouch of Douglas tends to mimic those of omental teratomas, namely abdominal pain. The radiation of pain of the patients back is likely from lumbosacral neuropathy, due to the compression of the lumbosacral plexus.$^{27}$

\section{Torsion}

Torsion of the pedicle is reported to be the most frequent complication of ovarian teratoma, occurring in $16.1 \%$ of cases. ${ }^{22}$ Torsion interferes with the blood supply of the involved organs. Venous congestion and aseptic inflammation of the tumor wall may thus result. In acute torsion, the tumor undergoes necrosis and subsequently atrophies due to ischemia. In subacute or chronic torsion the tumor may become adherent to adjacent structures with new collateral circulation formed. Infrequently, the tumor completely detaches from its pedicle, thus resulting in a parasitic dermoid cyst. Dermoid cyst is an infrequent cause of abdominal and flank pain, when it does occur, it is due to mass effect or ovarian torsion. The pain is related to the ischemic complication of the enlarged ovary twisting around its pedicle. ${ }^{29}$

\section{Chemical and Granulomatous peritonitis}

Inadvertent dermoid cyst rupture may result in chemical peritonitis $(3-7 \%)$, and surgical treatment may become necessary. ${ }^{28-30}$ Rupture of the cyst with spillage of its fluid content may be deleterious with teratomas. Chemical peritonitis and granuloma formation with intestinal obstruction have been reported after laparoscopic removal of benign cystic teratomas due to spillage. ${ }^{29}$ Adequate intra-abdominal isolation within an endobag to avoid the most common event of spillage during laparoscopic removal of dermoid cyst is now advocated by several investigators. ${ }^{29-31}$ $A$ retrospective study covering 20 years and covering 26 cases of intra-peritoneal spillage in 314 patients identified 2 patients with post-operative granulomatous peritonitis, giving an incidence of chemical peritonitis $8 \% .^{32}$ However the data from another retrospective study of 324 patients who underwent laparoscopic cystectomy and suffered spillage, with irrigation of the abdominal cavity documents a lower incidence $(0.3 \%) .{ }^{33}$ However, prospective controlled clinical trials with a large number of patients are necessary to compare conventional methods with laparoscopy in cases with teratomas and to assess more rare events like undetected malignancy, clinical peritonitis or excess adhesion formation.

\section{Small bowel obstruction with ovarian teratoma}

Ovarian teratomas are usually asymptomatic until they reach a significant dimension. Pressure effect, torsion and rupture of an ovarian cyst may present as an acute abdomen. A case has been reported in an elderly lady with small bowel obstruction due to a very large ovarian teratoma adherent to the intestine causing intestinal obstruction. ${ }^{34}$ Acute intestinal obstruction is a very rare complication of ovarian teratomas. It will mainly occur when a loop of a small bowel becomes adherent to the cyst and twist with the torsion of the cyst requiring intestinal resection. ${ }^{35,36}$

\section{Fistula formation with bowel}

Ovarian teratoma fistulating to the sigmoid colon causing great abdominal distention is an extremely rare case. Although there are numerous differential diagnoses, most of the diagnoses would become apparent after radiological work-up. Fistulation is a rare complication of mature cystic teratoma and urinary bladder is the most commonly affected organ. ${ }^{37,38}$ Malignant transformation is not a pre-requisite for fistulation. Inflammation related to previous sub clinical leakage 
of the cyst content is believed to be the etiology of fistulation in some of the previous reports. ${ }^{37,39}$ Both inflammation and direct infiltration by malignant cells had contributed to the formation of fistulation in a case report of a giant gas filled abdominal mass in an elderly female..$^{40}$ The presence of significant tumor bulk around the area of fistulation suggest tumor invasion being the pre- dominant factor. Malignant transformation arising from ovarian teratoma can rarely present as a surgical emergency with gross abdominal distension, resembling bowel pathology such as giant colonic diverticulum and duplication cyst. A case of benign cystic teratoma with fistula into the small and large bowel has been reported. A $10 \mathrm{~cm}$ dermoid cyst perforating into the small and large bowel is described in a 25 year old lady. ${ }^{8}$ A primary large bowel repair, small bowel resection with enblock left salphingo-oophorectomy and small bowel side to side re-anastomosis saved the lady. Awareness to the clinical and radiological findings in these cases is important to avoid further complications.

\section{Malignant transformation in a dermoid cyst}

Dermoid cysts contain tissue from all three germ cells with teeth, bone and neural tissue being found. ${ }^{1}$ Secondary malignancies may develop in any of the tissue derived from the three germ layers. Malignant transformation of the mature elements within the dermoid cyst is a rare complication, occurring in only $1-2 \%$ of cases with squamous cell carcinoma being the most common type (upto $80-90 \%$ ) followed by adenocarcinoma, carciniod, neuroblastoma, sarcoma, sarcocarcinoma and oesteocarcinoma. ${ }^{9,41-46}$ The malignant transformation of an ovarian mature cystic teratoma has been reported in an 80 years old lady with an unusual presentation and initial diagnostic dilemma of locally aggressive squamous cell carcinoma in an ovarian dermoid cyst with invasion into the distal rectum and anal canal causing rectal bleeding similar to presentation of anal squamous cell carcinoma. This type of tumor can behave in a locally aggressive manner and is resistant to adjuvant therapy. ${ }^{47}$

Neuro tissue occur with considerable frequency in mature cystic teratoma, and neuroblastoma arising in a mature cystic teratoma of the ovary have been reported. ${ }^{48}$ But the development of a malignant neural neoplasm in an ovarian tumor of this type is an event of exceptional rarity and literature review reports that an neuroblastoma cannot arise in a fully mature teratoma and the development of a malignant neural tumor indicate that immature neuro-epithelium element must have been present in the otherwise mature teratoma. This view would accord with the age distribution of malignant neural neoplasm of the ovary. The typical age group for immature teratoma is young patient less than 20 years of age where as malignant change in a fully mature ovarian teratoma occurs most commonly during the $5^{\text {th }}$ and $6^{\text {th }}$ decades of life. ${ }^{48}$ This age-related pattern supports the view that a malignant neural neoplasms can only arise from immature neuroepithelial tissue in an ovarian teratoma.

It is suggested that age is not necessary a prognostic indicator but may be useful in terms of raising suspicion of malignant transformation when an older women presents with what appears to be a benign dermoid cyst. Other risk factors include tumor diameter greater than $10 \mathrm{cms}$ and rapid growth. ${ }^{49}$ Al Rayyan et al in their publication concluded that regardless of the type of malignancy, the tumor size, the extent of the disease and the patient's age were the major factors governing the survival in these patients. ${ }^{46}$ It is recommended that a higher index of suspicion of malignancy is needed in managing dermoid cysts occurring in patients over the age of 45 years especially if rapidly growing or very large tumors greater than $10 \mathrm{~cm} .{ }^{46}$ Kelly and Scully reported that thickening of the cyst wall and adherence to surrounding structures should raise high index of suspicion for malignancy in a dermoid cyst. ${ }^{49}$

Stromal tumors arising from the mesodermal germ cells of a mature dermoid cyst are rarer than their epithelial counterparts but have been reported. Ngwalle et al described the typical case occurring in a post-menopausal women with an osteosarcoma arising in benign dermoid cyst. ${ }^{50}$ A combination of different malignancies arising in the same dermoid cyst or the incidence of more than one malignancy arising from one ovary is exceptionally rare. But different combinations have been reported in the literature. Hanada et al described the multiple malignancy arising from a dermoid cyst of the ovary namely squamous cell carcinoma and myxoid fibrous histiocytoma. ${ }^{51}$ Arora and Haldane reported a case of carcino-sarcoma arising in the dermoid cyst of the ovary comprising of adenocarcinoma and leiomyosarcoma. ${ }^{52}$ A unique combination of squamous cell carcinoma and osteosarcoma arising in mature dermoid cyst of the ovary have been reported. ${ }^{41}$ The pathogenesis of malignant transformation of one somatic cell type to another is not clearly understood. It seems that mature dermoid cyst most likely to undergo transformation of totipotential germ cells towards the formation of squamous cell carcinoma that might have later dedifferentiated into osteosarcoma. A large mature cystic teratoma containing carcinomatous and sarcomatous elements has been reported. Sarcoma alone or in combination with squamous carcinoma has been described arising in a mature cystic teratoma but a case of sarcoma arising in associated with adenocarcinoma is very rare. Adenocarcinomas are the second most common malignancies arising within the dermoid cyst 
and may display gastrointestinal phenotypes but lack the malignant stroma. ${ }^{53}$

The prognosis of patient with malignant transformation in teratoma is very poor with women dying within a year. Occasionally cases with prolonged survival have been reported. ${ }^{53}$ Poor prognostic factors include tumor dissemination, cyst wall invasion, ascites, spontaneous or accidental rupture, adhesions and tumor type other than squamous carcinoma. ${ }^{53}$

It is histologically difficult to diagnose this disease pre-operatively as neither serum tumor markers nor imaging with ultrasound or CT reliably predicts the specific diagnosis., CA19-9 is a tumor associated glycolipid ,frequently elevated in the serum of patients with gastrointestinal malignancies particularly of the pancreas. It is present in relatively high concentration in prostatic, gastric, amniotic fluid and excretions of pancreas and duodenum in individuals. CA19-9 could be increase in upto $50 \%$ of cases of dermoid cysts with malignant changes. ${ }^{54}$ Modern imaging techniques such as MRI shows the presence of solid or necrotic contrast-enhancing areas that may extend transmurally and show evidence of adherence to surrounding structures. ${ }^{55}$ Mature cystic teratoma of ovary frequently contain intestinal type epithelium, but they are rarely associated with complete intestinal wall. The association of mature cystic teratoma with mucinous cystadenoma is not unusual However the pathogenetic relationship between these two lesions remain unanswered. A mature cystic teratoma containing a complete colonic wall in continuity with an endocervica I type mucinous cystadenoma is reported. Both the mucinous cystadenoma and the colonic wall showed the typical histopathological and immuno-histochemical patterns of classical mucinous cystadenoma and normal colonic wall. The microscopic and immunohistochemical patterns of the transitional zone between colonic wall-like structure and mucinous cystadenoma stained positive for chromogranin suggesting that the mucinous cystadenoma most likely originated from colonic epithelium of the mature cystic teratoma. ${ }^{56}$

\section{Infection}

Mature cystic teratoma may be complicated by torsion, rupture, chemical peritonitis and malignant change but is rarely complicated by infection. Infection occurs in approximately $1 \%$ of mature cystic teratoma, the infecting organism most likely being coliforms. ${ }^{57}$ Actinomycosis, Brucella, Schistosomiasis, Salmonela has also been reported. ${ }^{58-64}$ It is more commonly seen in reproductive age but seen in post-menopausal women also. A tubo-ovarian abscess following a dilatation and curettage (D\&C) procedure in the setting of an ovarian dermoid cyst have been reported. ${ }^{64}$

\section{Homunculus in dermoid cyst}

In Latin, Homunculus means a structure resembling a miniature human body to designate a human being not produced by pregnancy and this definition is used in morphological entities. Such fetus like structure (homunculus) can be found in mature cystic teratoma. ${ }^{5}$ In some cases the cephalic region is more developed with cranium and cerebral cortical tissue. In some cases the caudal region including the lower extremities is typically more developed than the cephalic portion. ${ }^{5,65}$ In a case reported, the radiographic examination of the homunculus revealed a calcific density in the cephalic portion resembling temporal bone, zygomatic arch, temporomandibular joint and mandible. The caudal portion showed a tubular bony structure. ${ }^{5}$ This tumor should be distinguished from the more highly developed fetus-in-situ, a malformed parasitic monozygotic twin that is found inside the body of a living child or adult.

\section{Multiple recurrence of dermoid cyst}

In the literature it is observed that mature cystic teratoma can show recurrence with a rate of $3-4 \% .{ }^{66}$ In different reports it is emphasized the especially cysts with diameter less than $2 \mathrm{~cm}$ can be ignored during preoperative transvaginal ultrasonographic imaging but these cysts can be later be diagnosed as recurrence. It is realized that the recurrence rate was higher in the patients who were young at first diagnosis. At the same time, bilaterality and multi-locularity were observed more often in the recurrent cases. The recurrence occurs nearly 1-15 years after the first operation and the recurrence rate was $2-5 \%$ after ovary protected surgery. ${ }^{66}$ The regular follow-up of young patients has a clinical importance in the early detection of the recurrent masses and during the surgeries of the recurrent cases, the surgeon should be careful about the bilaterality or multilocularity of the tumor.

\section{Virilizing ovarian dermoid cyst with leydig cells}

Ovarian tumors causing virilization are exceedingly rare and mostly occur in post-menopausal women. In fact, there are no reported cases of virilization from a testosterone producing ovarian dermoid in the adolescent female age group. A case has been reported in 12 year old girl who has a large $35 \times 19$ $X 12 \mathrm{~cm}$ ovarian mature cystic teratoma arising from her right ovary. The patient also displayed evidence of masculinization demonstrated by a deepening voice and clitoromegaly. The dermoid was producing large amounts of testosterone from a nest of leydig cells found pathologically in the mass. ${ }^{67}$ Benign cystic 
teratomas can produce active hormones, albeit rarely. This is a finding important to consider when ovarian cystectomy is performed for removal of a benign cystic teratoma.

\section{CONCLUSION}

The cornerstone of the study of ovarian teratoma is that the evaluation of possible malignancy, accidental rupture/ hemorrhage, rapid growth, doubtful infiltration, large size, origin and adjacent structures is based on detailed preparation. Despite the large size, there is one third chance of finding a malignancy, suggesting that all of these large masses should be removed intact wherever possible. Prospective controlled clinical trials with a large number of patients are necessary to compare conventional methods with laparoscopy in cases with teratomas and to assess more rare events like undetected malignancy, chemical peritonitis, or excess adhesion formation.

\section{REFERENCES}

1. Ayhan A, Bukulmez O, Genc C, Karamursel BS. Mature Cystic teratoma of the ovary: Case series from one institution over 34 years. Eur J Obstet Gynaecol Reprod Biol. 2000;88:153-7.

2. Comerci JT Jr, Licciardi F, Bergh PA, Gregori C, Breen JL. Mature Cystic teratoma: A clinical pathologic evaluation of 513 cases and review of the literature. Obstet Gynecol. 1994;84:22-8.

3. Outwater EK, Seigelma FS, Hunt JL. Ovarian teratoma: Tumour types and imaging characteristics. Radiographics. 2001;21:475-90.

4. Choi DJ, Wallace EC, Fraise AE, Baiyee D. Best cases from the AFIP: intrarenal teratoma. Radiographics. 2005;25:481-5.

5. Lee YH, Kin SG, Choi SH, Kim IS, Kim SH. Ovarian mature cystic teratoma containing homunculus: A case report. J Korean Med Sci. 2003;18:905-7.

6. Ashley DJ. Origin of teratoma. Cancer. 1973;32:390-4.

7. Long-yun Ye, Jing-Jing W, Da-Ren L, Guo-Ping D, Li-Ping C. Management of Giant ovarian teratoma: A case series and review of the literature. Oncology letters. 2012;4:627-76.

8. Walter V, Astid R, Nelken RS. Benign cystic ovarian teratoma with a fistula into the small and large bowel. Obstetrics and Gynecology. 2012;119:434-6.

9. Hurwitz JL, Fenton A, McCluggope WG, McKenna S. Squamous cell carcinoma in a dermoid cyst of the ovary: a case series. BJOG. 2007;114:1283-7.

10. Caspi B, Appelman Z, Robinersen D, Zatel $Y$, Tulaudi $T$, Shoham $Z$. The growth pattern of ovarian dermoid cyst: A prospective study in premenopausal and post-menopausal women. Fertility and sterility. 1997:68:501-5.

11. Tindal UR. Jeffcoate's Principles of Gynaecology, 5th edition. 1987:466.

12. Hasanzadeh M, Tabare S, Mirzaean S. Ovarian dermaoi cyst: Professional Med J. 2010;17(3):512-15

13. Monk BE, Bayliss R, Isaacs AJ. Giant ovarian dermoid cyst masked up obesity. Post graduate medical journal. 1980;56:748- 9

14. O'Hanlan KA. Resection of a 3032 pound ovarian tumour. Gynaecologic Oncology. 1994;54:365-71.
15. Schuetz MJ $3^{\text {rd }}$, Elsheikh TM. Dermoid cyst (mature cystic teratoma) of the cecum. Histologic and cytologic features with review of the literature. Arch Pathol lab Med. 2002:126:97-9.

16. Sakurai Y, Graguchi T, Imazu H et al. Submucosal dermoid cyst of the rectum: report of a case. Surg today. 2003;30:195-8.

17. Vermeulen BJ, Widgren S, Gur V, et al. Dermoid cyst of the pancreas. Case report and review of the literature. Gastroen Clin Biol. 1990;14:1023-5.

18. Goldmakher G, Lee S, Coughlin B. Mature cystic teratoma(dermoid cyst) of the mesentery: http/ www.appliedradiology.com/Issues2005/04/cases/ mature-cystic-teratoma-(dermoid cyst)-of-the-mesentery. aspx

19. Aderjou EA, Adekunle OO, Mandubuko GC. Mesenteric dermoid cyst simulating hepatocellular carcinoma in Nigerian male: A case report. East Afr Med J. 1980;57:508-11.

20. Torreggiani WC, Bremer C, Nicallef M, O' Laoide R. Case report: Caesal Volvulus in association with a mesenteric dermoid. Clin Radio. 2001;56:430-2.

21. Peterson WF, Prevost EC, Edmunds FT, Hundley JM, Morris FK. Benign cystic teratoma of ovary. A clinical study of 1007 cases with a review of literature. AmJ obstet Gynecol. 1955;70:368-82.

22. Khoo CK, Chua SYI, Siow YMA, Shorn SMB. Extragonad Dermoid cysts- a review and report. Singapore Journal of Obstetrics and Gynaecology. 2008;39(1):17-20.

23. Ushakov FB, Meirow D, Prus D, Gibson E, Berishushan A, Rojansky N. Paracytic ovarian dermoid tumour of the omentum- A review of the literature and report of two new cases. Eur J Obstet Gynecol Reprod Biol. 1998;81:77-82.

24. Kusak M, Mikuni M. Ectopic ovary: a case of auto amputated ovary with mature cystic teratoma into the cul-de-sac. J Obstet Gynecol Res. 2007;33:368-7.

25. Wahba AK. Unreported location and presentation for a parasitic ovarian dermoid cyst: A case report. Middle east fertility society Journal. 2010;15:216-8.

26. Gupta P, Kumar S, Roy KK, Sharma JB, Singh N. Parasitic ovarian dermoid cyst stuck to the anterior abdominal wall managed laparoscopically. Arch Gynecol Obstet. 2009;281:377-8. 
27. Otigbah C, Thompson MO, Lowe D, Setchell M. Mobile globules in benign cystic teratoma of the ovary. BrJ Obstet Gynecol, 2000;107:135-8.

28. Guleria K, Sahu B, Suneja A, Yadab P, Agarwal N. Parasitic ovarian dermoid tumour. Aust Nz J Obstet Gynaecol. 2002;42:558-9.

29. Kocak M, Dilbaj B, Ozturk N, Deole S, Altay M, Dilbaz S, Haberal A. Laparoscopic management of ovarian dermoid cysts: A review of 47 cases. Ann Saudi Med. 2004;2415:357-60.

30. Coccia ME, Becattini C, Bracco GL, Scarselli G. Acute abdomen following dermoid cyst rupture during transvaginal ultrasonographically guided retrieval of oocytes. Hum Reprod. 1996;11:1897-9.

31. Langebrekke A, Urnes A. Post-operative complication after laparoscopic removal of benign cystic teratomas. Gynecol Endosc. 1994;3:245-6.

32. Kondo W, Bocordel N, Cotte B, Tran X, Botchorishvili R, Jordan $\mathrm{K}$, et al. Does prevention of intraperitoneal spillage when removing a dermoid cyst prevent granulomatous peritonitis? BJOG. 2010;117:1027-30.

33. Caldas C, Sitzmann J, Trimble CI, McGuire WP III. Synchronous mature teratoma of the ovary and liver: A case presenting 11 years following chemotherapy for immature teratoma. Gynecol Oncol 1992;47:385-90.

34. Al-Harfoushi R, Abdulaziz AH, Andrabi SIH, Pattorson B, Whiteside M. Ovarian teratoma presenting as small bowel obstruction in elderly lady- A case report. International Journal of Surgery case reports. 2001;2:6-8.

35. Gupta RK, Gupta P. Cystic ovarian teratoma in a girl of 5 years presenting an acute intestinal obstruction. J Indian Med Assoc. 1997;68(11):235-6.

36. Wakelin SJ. An unusual case of small bowel obstruction. The Internet Journal of Gastroentrology. 2007;6:1528-8323.

37. Shiels WE, Dueno F, Hernandez E. Ovarian dermoid cyst complicated by an entero-ovarian fistula. Radiology. 1986; 160:443-4.

38. Stern JL, Busuna J, Rosenshem NB, Woodruff JD. Spontaneous rupture of benign cystic teratoma. Obstet Gynecol. 1981;57:363-6.

39. Cebesoy FB, Baskonus I, Mete A, Vutlar I, Aybash N. Benign ovarian dermoid cyst complicated with rectal fistula formation: An unusual case. Arch Gynecol Obstet. 2009;279:179-81.

40. Chong HMD, Lee FYJ, Lo A, Li CMJ. A giant gas filled abdominal mass in an elderly female: A case report. World Journal of Gastroenterology. 2011;17(3) 3679-62.

41. Nandyala PA, Bui MM, Caracciolo JT, Hakam A. Squamous Cell Carcinoma and osteosarcoma arising from a dermoid cyst- A case report and review of literature. Int J Clin Patol. 2010;3(3):313-8.

42. Powell JL, Stinson JA, Connor GP, Shiro SB, Mattison M. Squamous cell carcinoma arising in a dermoid cyst of the ovary. Gynecol Oncol. 2003;89:526-8.
43. Fox H, Langley FA. Tumours of the ovary. London Heineman Medical, 1981.

44. Chiarg AJ, La V, Peng J, Yu KJ, Teng NN. Squamous cell carcinoma arising from mature cystic teratoma of the ovary. Int J Gynecol Cancer. 2011;21(3):466-74.

45. Reid H, Walt JVD, Fox H. Neuroblastoma arising in a mature cystic teratoma of the ovary. J Clin Pathol. 1983;36:68-73.

46. Basqul A, Gokaslar H, Kavak ZN, Guducu N, Eren F. Squamous cell carcinoma developing in a huge dermoid cyst of the ovary in a 80 years old woman- Case report. Eur J Gynecol Oncol. 2007;28(1):63-6.

47. Al-Rayyan FS, Dugoun WJ, Sawalha MS, Nascinento MC, Patter S, Dalrymple CJ, et al. Secondary Malignancies in Ovarian dermoid cyst. Saudi Med J. 2009;30(4):524-8.

48. Lee YC, Abulafia O, Montalto N, Holcomb K, Matheus R, Golwv RGN. Malignant transformation of an ovarian mature cystic teratoma presenting as a rectal mass. Gynecol Oncol. 1999,75(3):499-503.

49. Kelly RR, Scully RE. Cancer developing in dermoid cyst often ovary- A report of 8 cases, including a carcinoid a leiomyosarcoma. Cancer. 1961;14:989-1000.

50. Ngwalla K, Hirakawa T, Tsuneyoshi M, Enjosi M. Osteosarcoma arising in a benign dermoid cyst of the ovary. Gynecol oncol. 1990;37:143-7.

51. Hanada M, Tsujimura T, Shimizu H. Multiple malignancies (Squamous cell carcinoma and sarcoma) arising in a dermoid cyst of the ovary. Acta Pathol. Jpn. 1981;31(4):681-8.

52. Arora DS, Haldare S. Carcinoma arising in a dermoid cyst of the ovary. J Clin Pathol. 1996;49:519-21.

53. Leeda G, Fugita M, Ogawa H, Sawada M, Inoue M, Tanizawa O. Adenocarcinoma in a benign cystic teratoma of the ovary: Report of a case with a long survival period. Gynecol Oncol. 1993;48:259-63.

54. Takemori M, Nishimura R. MRI findings of an ovarian dermoid cyst with malignant transformation. Mogn Reson Med Sci. 2003;2:105-8.

55. Tang P, Soukkary S, Kahn E. Mature cystic teratoma of the ovary associated with complete colonic wall and mucinous cyatadenoma. Annals of clinical and laboratory science. 2003;33:465-70.

56. Hasanzadeh M, Jabare S, Mirzaen S. Ovarian Dermoid cyst. Professional Med J. 2001;17(3):512-5.

57. Turner RJ, Day PL. Torsed infected dermoid cyst with concurrent ectopic pregnancy. Military Medicine. 1986;151(3):180-99.

58. Melato M, Muuse MM, Hussein AM, Falconieri G. Schistosomiasis in a cystic teratoma of the ovary. Clinical and experimental Obstetrics and Gynecology. 1987;14(1):57-9.

59. Dauplat J. Ovarian abscess: A case of dermoid cyst with secondary infection. Revve francaise de Gunecologie d' Obstetrique. 1993;88(1):23-6.

60. Gwaydah M, Khalil A, Shamsuddine N, Matar F, Araj GF. Brucella infected 'ovarian dermoid' cyst causing brucellosis infection. 1998;26(2):131-2. 
61. Lucas MJ, Cawdell GM. Actinomycosis infection of a dermoid cyst mimicking pelvic malignancy. Aust $\mathrm{Nz} \mathrm{J}$ Obstet Gynecol. 1995;35(2):225-6.

62. Matsubayashi T, Hamajima T, Asano K, Mijukanii A, Seguchi M, Kohno C, Inkai K, et al. Salmonella infection of an Ovarian dermoid cyst. Pediatr Int. 2001;43(2):164-5.

63. Luk J, Quaas A, Garner E. The superinfection of a dermoid cyst. Infectious Disease in Obstetrics and Gynaecology Infect Dis Obstet Gynecol. 2007;2007:41473-4.

64. Azoury RS, Jabayli NW, Barakat BY. Dermoid cyst of ovary containing fetus like structure. Obstet Gynecol.
$1973 ; 42: 887-91$.

65. Alanbay I, Coksuer H, Ercan M, Karasahin K, Keskin V, Baser I. Multiple recurrent mature cystic teratoma of the same ovary: A case report and literature review. The Medical Journal of kecatepe, 2011;12:8-12.

66. Hoffman JG, Strickland JL, Yin J. Virilising ovarian dermoid cyst with leydig cells. J Pediatr Adolesc Gynecol. 2009,22(3):39-40. 